\title{
Pengembangan Web Service Sistem Informasi Sekolah
}

\author{
Za'imatus Sa'diyah', Kevin Elmy Aziz ${ }^{2}$, Muhammad Hudan Dardiri' ${ }^{3}$ Ainul Yaqin ${ }^{4}$ \\ Jurusan Teknik Informatika, Fakultas Sains dan Teknologi \\ Universitas Islam Negeri Maulana Malik Ibrahim Malang \\ Jalan Gajayana No. 50 Malang 651544 Telp. +62 (341) 551-354 \\ 16650040@student.uin-malang.ac.id,16650087@student.uin-malang.ac.id, \\ 16650115@student.uin-malang.ac.id,yaqinov@ti.uin-malang.ac.id
}

\begin{abstract}
School information system is a system that provides information to support the operational, management, and decision making functions of an organization. Information sources within the information system that support day-to-day management operations such as transaction processing, status clarification, and so forth. School information systems generally consist of a variety of systems, including academic, financial, library and staffing systems. With a variety of systems in a school information system, it is necessary to integrate between systems aimed at avoiding data duplication in each system and increase system flexibility which can be achieved by utilizing web service technology. The purpose of this research is to design a web service on information systems schools that comply with the National Education Standards (SNP) use the REST web service architecture. The results of the development of an information system web service design that is by mapping class diagrams that will be made in the design of school web services by adding modules to JIBAS with the Minister of National Education Regulation in accordance with 8 BSNP standards.
\end{abstract}

Keywords: Web service, Information system, REST API, JIBAS

\begin{abstract}
Abstrak
Sistem informasi sekolah merupakan sistem yang menyediakan informasi untuk mendukung kegiatan operasional, manajemen, dan fungsi pengambilan keputusan dari suatu organisasi. Sumber informasi yang ada di dalam sistem informasi tersebut yang mendukung operasi manajemen seharihari seperti pengolahan transaksi, penjelasan status, dan lain sebagainya. Sistem informasi sekolah secara umum terdiri dari berbagai macam sistem, diantaranya seperti sistem akademik, keuangan, perpustakaan, dan kepegawaian. Dengan adanya berbagai system dalam sebuah sistem informasi sekolah, maka perlu adanya integrasi antar sistem yang bertujuan untuk menghindari adanya duplikasi data di setiap sistem dan meningkatkan fleksibilitas sistem yang mana hal itu bisa dicapai dengan memanfaatkan teknologi web service. Tujuan penelitian ini adalah merancang web service pada sistem informasi sekolah yang sesuai dengan Standar Nasional Pendidikan (SNP) menggunakan arsitektur web service REST. Hasil pengembangan rancangan web service sistem informasi yaitu dengan memetakan class diagram yang akan dibuat pada perancangan web service sekolah dengan menambahkan modul modul pada JIBAS yang mengacu pada Peraturan Menteri Pendidikan Nasional yang sesuai dengan 8 standar BSNP.
\end{abstract}

Kata kunci: Web service, Sistem informasi, REST API, JIBAS

\section{PENDAHULUAN}

Kehadiran Teknologi Informasi telah memberikan kemudahan pada aspek kehidupan dengan kecanggihan teknologi informasi. Beberapa fasilitas teknologi dimanfaatkan untuk mempermudah dalam mendapatkan informasi, salah satunya sistem informasi sekolah. Beberapa sistem yang terdapat pada sistem informasi sekolah, seperti akademik, keuangan, perpustakaan, dan pegawai yang di dalamnya terdapat modul - modul di setiap sistem yang ada, dengan adanya 
beragam sistem yang digunakan di setiap unit, perlu adanya integrasi data antar sistem. Integrasi dapat diartikan adanya saling keterkaitan antara satu sistem dengan sistem yang lain.

Integrasi data merupakan proses menggabungkan atau menyatukan data yang berasal dari sumber yang berbeda dalam rangka mendukung manajemen informasi dan mendukung pengguna untuk melihat kesatuan data. Data yang digabungkan merupakan data dari berbagai sumber database yang berbeda ke dalam sebuah penyimpanan seperti gudang data (data warehouse). Syarat integrasi data dapat dipenuhi dengan berbagai cara seperti konsisten dalam penamaan variabel, konsisten dalam ukuran variabel, konsisten dalam struktur pengkodean dan konsisten dalam atribut fisik dari data. Masalah- masalah yang ada pada integrasi data yaitu heterogenitas data, otonomi sumber data, kebenaran dan kinerja query/permintaan sedangkan integrasi sistem merupakan suatu konsep sistem yang dapat saling berhubungan satu dengan yang lain dengan berbagai cara yang sesuai dengan keperluan, hal ini sangat bermanfaat bila suatu data dalam file suatu sistem diperlukan juga oleh sistem yang lainnya atau output suatu sistem menjadi Input sistem lainnya. Keuntungan dari integrasi sistem ini adalah membaiknya suatu arus informasi dalam sebuah organisasi. Sehingga integrasi yang akan dilakukan pada penelitian ini yaitu dengan memanfaatkan teknologi web service.

Web service memiliki kelebihan yaitu dapat melakukan pertukaran data lintas platform dan memiliki bahasa independen. Arsitektur web service yang paling banyak digunakan adalah Simple Object Access Protocol (SOAP) dan Representational State Transfer (REST). Rancangan web service yang digunakan adalah sesuai dengan Standar Nasional Pendidikan (SNP) menggunakan arsitektur web service REST.

\section{METODOLOGI PENELITIAN}

\subsection{Sistem Informasi}

Sistem informasi secara umum dapat didefinisikan sebagai kumpulan hal atau elemen yang saling bekerja sama atau yang dihubungkan dengan cara cara tertentu sehingga membentuk satu kesatuan untuk melaksanakan suatu fungsi guna mencapai suatu tujuan. Sistem mempunyai karakteristik atau sifat sifat tertentu, yaitu : komponen sistem, batasan sistem, lingkungan luar sistem, penghubung sistem, masukan sistem, keluaran sistem, pengelolahan dan sasaran sistem. [1]

\subsection{Web Service}

Saat ini telah berkembang sebuah teknologi yang memungkinkan bentuk akhir dari sebuah program atau aplikasi komputer adalah sebuah service atau fungsi yang melakukan sebuah tugas atau proses yang spesifik dan dikenal dengan istilah Web-Service. Konsep ini sebenarnya bukanlah sebuah konsep yang baru, berbagai teknologi telah dikembangkan untuk mewujudkan kebutuhan akan koneksi atau hubungan antar aplikasi. Adanya Web-Service memudahkan perpaduan fungsi dalam membangun sebuah program aplikasi tanpa bergantung 
lagi pada sistem operasi maupun bahasa pemrograman yang digunakan (Tutorial Point). Hal ini dimungkinkan karena web service berkomunikasi menggunakan sebuah standar standar format data yang universal yaitu XML dan menggunakan protokol Simple Object Access Protocol (SOAP). Dengan adanya web service menggunakan format data XML, maka web service juga mewariskan sifat multi-tier dari XML sehingga memungkinkan terjadinya integrasi antar web service atau aplikasi.[2] Web service memiliki banyak kelebihan yaitu dapat melakukan pertukaran data dan memiliki bahasa yang independen [3]. Arsitektur web service yang paling banyak digunakan adalah SOAP dan REST [4].

\subsection{API}

Dalam implementasinya semua web service menggunakan API yang mana web service memberi kemampuan interaksi antar dua atau lebih perangkat atau aplikasi melalui jaringan. Sedangkan API bertindak sebagai penghubung antara dua aplikasi berbeda sehingga bisa berkomunikasi satu sama lain baik dengan ataupun tanpa jaringan. Web service hanya menggunakan 3 style yaitu SOAP, REST, atau XML-RPC untuk berkomunikasi sedangkan API dapat menggunakan style apapun.

Application programming interface (API) merupakan suatu dokumentasi yang terdiri dari interface, fungsi, kelas, struktur dan sebagainya untuk membangun sebuah perangkat lunak. Dengan adanya API ini, maka memudahkan programmer untuk "membongkar" suatu software, kemudian dapat dikembangkan atau diintegrasikan dengan perangkat lunak yang lain. API dapat dikatakan sebagai penghubung suatu aplikasi dengan aplikasi lainnya yang memungkinkan programmer menggunakan sistem function. Proses ini dikelola melalui sistem operasi. Keunggulan dari API ini adalah memungkinkan suatu aplikasi dengan aplikasi lainnya dapat saling berhubungan dan berinteraksi .[5]

\subsection{JIBAS}

JIBAS (Jaringan Informasi Bersama Antar Sekolah) adalah sebuah CMS (Content Management System) yang dibuat oleh Yayasan Indonesia Membaca dan bertujuan untuk memudahkan lembaga sekolah untuk memanajemen sistem informasi akademik, keuangan, perpustakaan, kepegawaian, pelaporan, dsb. JIBAS juga dibuat untuk memudahkan guru maupun orangtua untuk mengkontrol siswa dengan bantuan SMS Gateway.

\subsection{Studi Yang Pernah Dilakukan}

Untuk memberikan landasan yang kuat terhadap penelitian ini, maka terdapat beberapa penelitian sebelumnya yang sedang dan telah dilakukan oleh peneliti sebagai berikut:

a. Penelitian mengenai web service ini dilakukan oleh Tansil Choiri, Nataniel Dengen, Islamiyah, berjudul Web Service Untuk Web Profil Smp Negeri 2 Rantepao Toraja Utara, Prosiding Seminar Ilmu Komputer dan Teknologi Informasi Tahun 2017,[6] Hasil penelitian : Dengan dikembangkannya web service pada web profil SMPN 2 Rantepao dapat dimanfaatkan untuk 
diintegrasikan dengan aplikasi atau website lainnya. Sehingga website sekolah tersebut tidak hanya menjadi media informasi saja, akan tetapi juag bisa dimanfaatkan dalam bidang lain seperti menghubungkan website profil ke dalam aplikasi E - Learning.

b. Penelitian selanjutnya oleh Astika AyuningTyas, Ahmad Ashari, Pemanfaatan Teknologi Web Service Untuk Integrasi Sistem Layanan Materi Pelayanan Terdistribusi, Jurnal Angkasa Jurusan Ilmu Komputer dan Elektronika, FMIPA UGM, Yogyakarta Tahun 2016,[7] hasil dari penelitian tersebut Dengan diterapkannya teknologi web service, telah berhasil dibangun sistem layanan materi pelajaran yang menyediakan informasi beragam dan saling terintegrasi dalam satu sistem, sehingga beberapa sistem dengan struktur data dan platform yang berbeda dapat saling berkomunikasi dalam mendistribusikan informasi. Integrasi layanan materi pelajaran antar sekolah dapat menghasilkan informasi yang saling melengkapi guna mendukung kebutuhan pengguna yang beragam tanpa dibatasi perbedaan lingkungan.

\subsection{Metode Penelitian}

Adapun metodologi penelitian yang digunakan pada penelitian ini adalah metode SDLC (System Depelopement Life Cycle).[8] SDLC merupakan metodologi klasik yang digunakan untuk mengembangkan, memelihara dan menggunakan sistem informasi [9-10]. Metode ini menggunakan pendekatan sistem yang disebut pendekatan air terjun (waterfall approach) yang menggunakan beberapa tahapan dalam mengembangkan sistem. Adapun tahapan dalam SDLC (System Development Life Cycle) sebagai berikut:

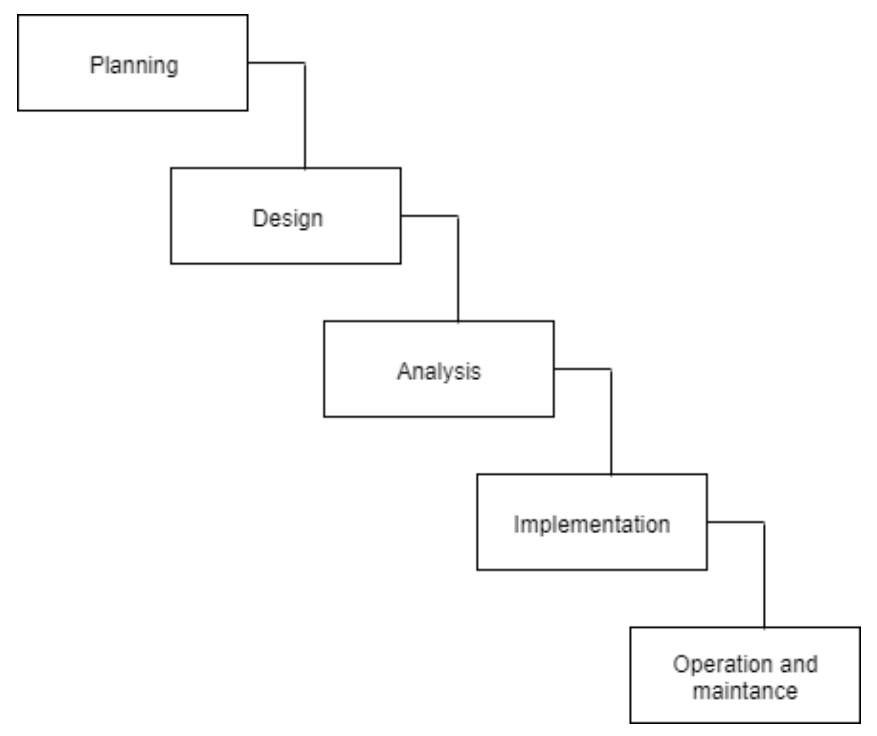

Gambar 1. Metode SDLC Model Waterfall

a. Tahap Perencanaan Sistem (System Planning) merupakan tahapan awal dalam pengembangan sistem. Pada penelitian sebelumnya telah dilakukan 
perencanaan manajemen proyek (project management plan) yang memuat perkiraan kebutuhan kebutuhan sumber daya seperti perangkat fisik, manusia, metode.

b. Tahap Analisis Sistem (System Analysis) merupakan tahapan dimana data yang dikumpulkan oleh penulis dalam bentuk data kualitatif yang diperoleh dari hasil studi literatur dari berbagai penelitian serupa, Kemudian data tersebut digunakan sebagai acuan dalam pembuatan fitur-fitur sistem.

c. Tahap Perancangan/Desain Sistem (System Design). Tahap desain sistem merupakan tahapan setelah analisis sistem yang menentukan proses dan data yang diperlukan oleh sistem. Dalam penelitian ini dilakukan perancangan sistem dengan membuat alur sistem menggunakan DFD (Data Flow Diagram) dan ERD (Entity Relationship Diagram).

d. Tahap Penerapan/Implementasi Sistem (System Implementation). Tahap implementasi merupakan tahapan konversi dari hasil rancangan menjadi bentuk sistem menggunakan script/code. Penulis menggunakan bahasa markup HTML5 (HyperText Markup Language 5) CSS3 (Cascading Style Sheet 3) dan CSS Framework Bootstrap 4. Bahasa Pemrograman PHP versi 7, Javascript, dengan text editor pendukung Sublime, serta basis data yang di gunakan adalah MySQL.

e. Tahap Percobaan (Testing). Melakukan uji coba terhadap semua fungsifungsi sistem, agar sistem bebas dari eror dan hasilnya sesuai dengan kebutuhan yang sudah didefinisikan sebelumnya. Pada tahap ini proses testing dilakukan dengan menggunakan metode Black-Box Testing.

f. Analisis Efektivitas Sistem Melakukan analisis terhadap efektivitas sistem terkait kualitas sistem, kualitas informasi, kepuasan pengguna, dan manfaat sistem bagi pengguna, yang selanjutnya diolah dan dianalisis dengan teknik penarikan kesimpulan

\section{HASIL DAN PEMBAHASAN}

\subsection{Tahap Perencanaan}

Pada tahap perencanaan diperoleh data berupa modul-modul yang ada di dalam JIBAS sebagai data awal dalam pengembangan web service, sedangkan data lainnya diperoleh dari standar yang ada di BSNP, dimana data tersebut akan dilakukan proses analisis kebutuhan.

\subsection{Tahap Analisis Kebutuhan}

Kebutuhan yang di analisis berupa analisis modul - modul sistem pada pengembangan rancangan web service sistem informasi sekolah yang sesuai dengan Standar Nasional Pendidikan (SNP) terdapat 8 standar[11]. Peneliti menggunakan 8 standar tersebut untuk memetakan class diagram yang akan dibuat pada perancangan web service sekolah. Berikut merupakan isi dari 8 standar tersebut :

a) Standar isi

b) Standar kompetensi lulusan

c) Standar proses pendidikan

d) Standar sarana dan prasarana 
e) Standar pengelolaan

f) Standar pembiayaan pendidikan

g) Standar penilaian pendidikan

h) Standar pendidik dan tenaga kependidikan

Setelah diperoleh 8 standar tersebut, nantinya akan dilakukan proses analisis hasil terhadap rancangan web service meliputi entitas yang ada dan keterkaitan kebutuhan antar sistem informasi sekolah. Sesuai dengan kebutuhan sekolah, beberapa sistem yang akan di analisis yaitu sistem akademik, sistem perpustakaan, sistem keuangan, dan sistem kepegawaian.

\subsection{Tahap perancangan sistem}

Perancangan sistem dilakukan dengan merancang arsitektur web service pada sistem informasi sekolah yang berbentuk class diagram. Perancangan sistem pada proses ini bertujuan untuk memenuhi kebutuhan dan proses yang terdapat di standar nasional pendidikan. Sistem informasi sekolah yang ideal meliputi sistem akademik, keuangan, perpustakaan, dan kepegawaian yang masing-masing di setiap sistem itu menjalankan fungsinya untuk memenuhi segala kebutuhan di sekolah. Berikut ini merupakan rancangan web service dalam bentuk class diagram.

\section{a. Akademik}

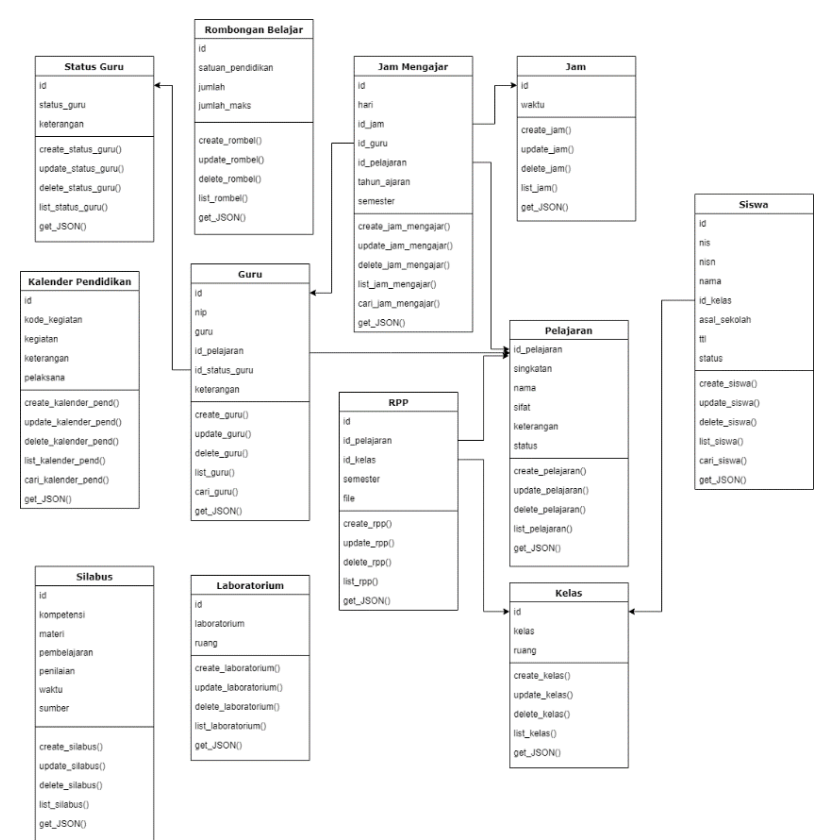

Gambar 2. Class diagram bagian akademik

Rancangan sistem yang ada pada bagian akademik didapatkan berbagai macam entitas yang akan digunakan pada proses akademik sekolah diantaranya seperti penerimaan siswa baru, pendataan guru dan pelajaran, penjadwalan, kesiswaan, presensi, penilaian dan pelaporan. 


\section{b. Perpustakaan}

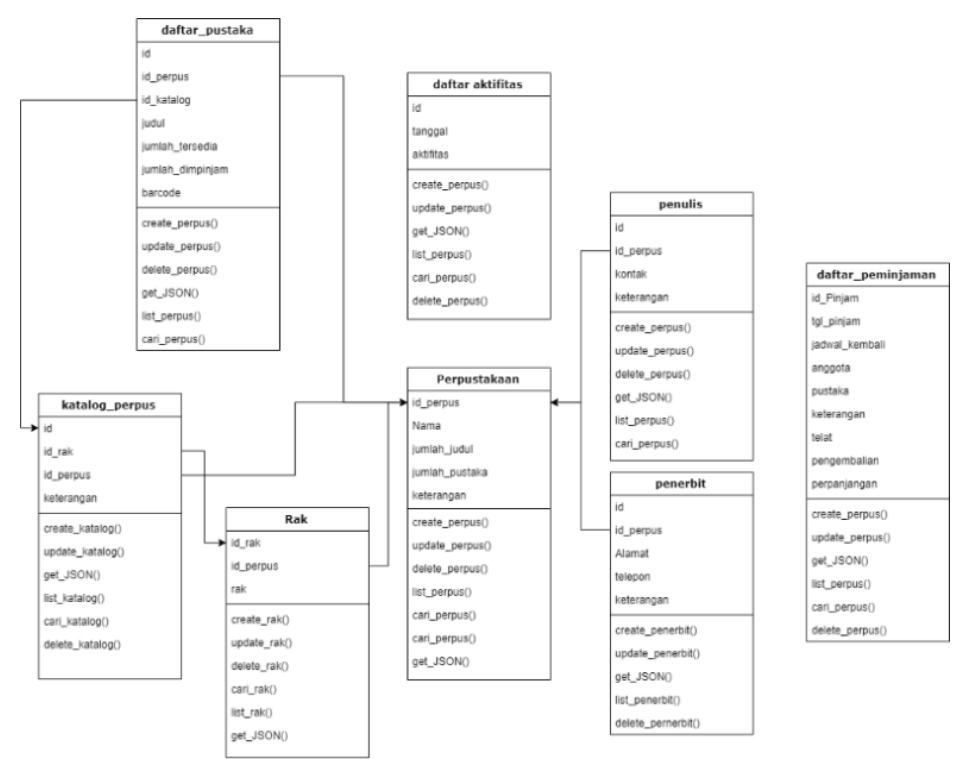

Gambar 3. Class diagram bagian perpustakaan

Rancangan sistem yang terdapat pada bagian sistem perpustakaan, menyimpan berbagai macam entitas yang akan digunakan pada proses yang menyangkut aktivitas di dalam perpustakaan seperti pustaka, peminjaman, pengembalian, dan riwayat aktivitas.

\section{c. Keuangan}

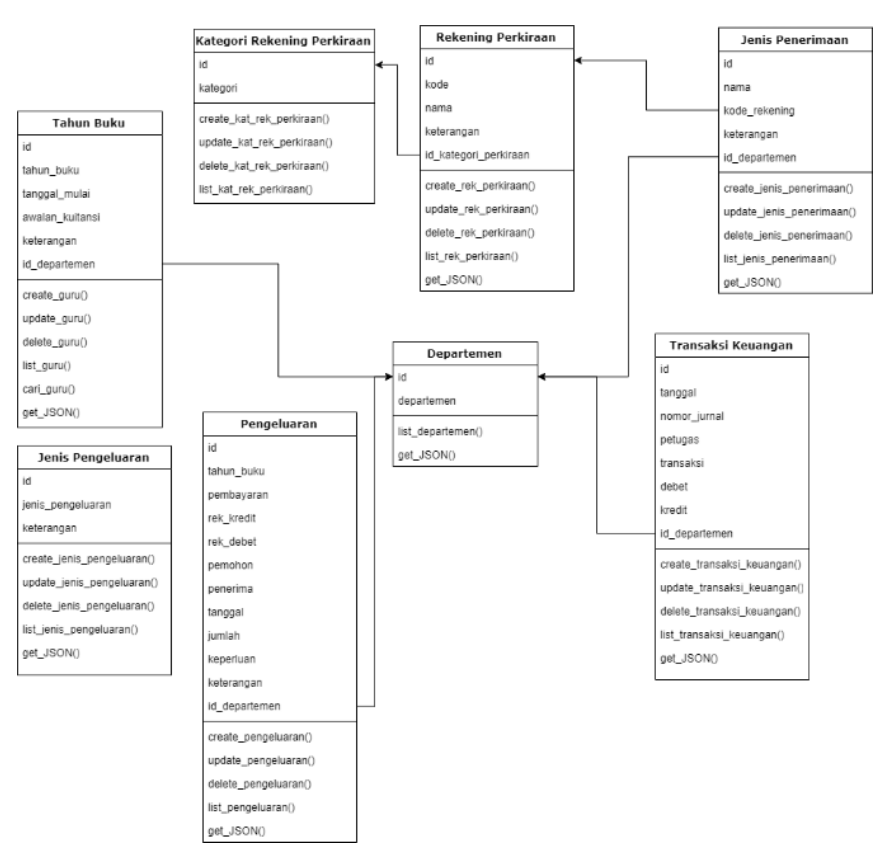

Gambar 4. Class diagram bagian keuangan. 
Pada bagian sistem keuangan terdapat berbagai macam entitas yang akan digunakan pada proses yang menyangkut keuangan sekolah diantaranya penerimaan, pengeluaran, tabungan, tabungan, inventori dan laporan keuangan.

\section{d. Kepegawaian}

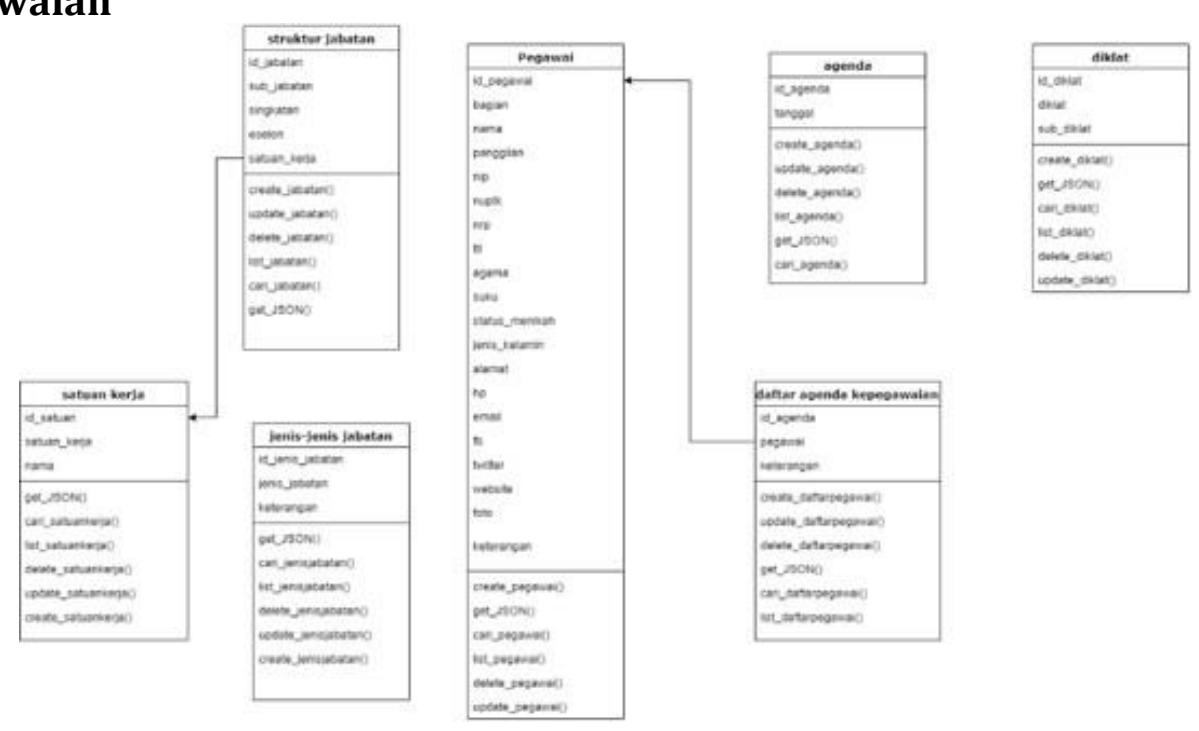

Gambar 5. Class diagram bagian kepegawaian.

Pada rancangan sistem kepegawaian terdapat berbagai macam entitas yang akan digunakan pada proses yang berkaitan dengan kepegawaian, diantaranya manajemen kepegawaian, penjadwalan agenda kepegawaian, struktur organisasi, diklat, dan presensi.

\subsection{Modul modul di dalam sistem}

Setelah dilakukan proses perancangan pada web service sistem informasi sekolah, di dapatkan sistem yang saling terintegrasi yaitu akademik, keuangan, perpustakaan, dan kepegawaian yang terdapat modul-modul di dalamnya. Berikut ini merupakan isi dari setiap modul yang ada pada rancangan web service sistem informasi sekolah.

a) Bagian sistem akademik memuat modul - modul di dalamnya yaitu rombongan belajar, silabus, status guru, jam mengajar, jam, siswa guru, kalender pendidikan, pelajaran, rpp, laboratorium, , kelas.

b) Bagian sistem keuangan memuat modul - modul seperti tahun buku, kategori rekening perkiraan, rekening perkiraan, jenis penerimaan, transaksi keuangan, departemen, pengeluaran, jenis pengeluaran.

c) Bagian sistem pegawai memuat modul - modul di dalamnya yaitu satuan kerja, struktur jabatan, pegawai, jenis-jenis jabatan, agenda, daftar agenda kepegawaian, diklat.

d) Bagian sistem perpusatakaan terdapat beberapa modul di dalamnya, yaitu daftar pustaka, katalog perpus, daftar aktifitas, rak, perpustakaan, penulis, penerbit, daftar peminjaman. 


\subsection{Tahap Implementasi}

\section{a. Sistem Informasi Akademik Sekolah}

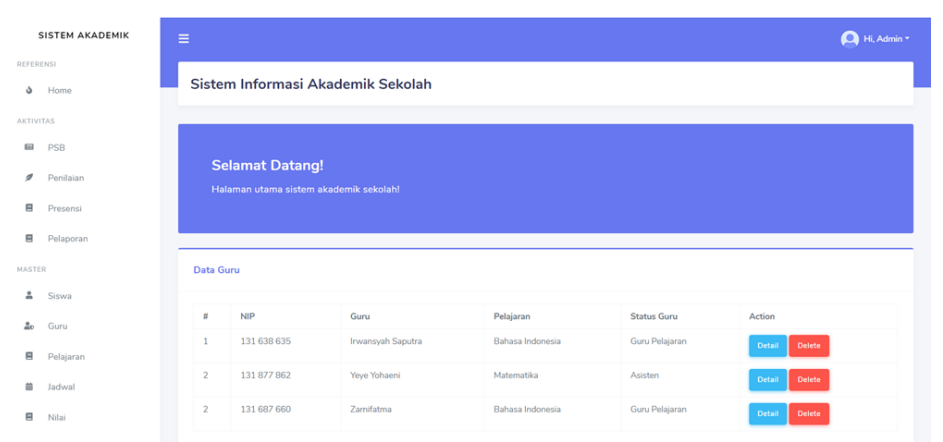

Gambar 6. Tampilan prototype sistem akademik

Pengembangan rancangan web service sistem informasi sekolah pada bagian akademik sekolah terdapat beberapa aktivitas di dalamnya seperti PSB, Penilaian, Presensi, dan Pelaporan :

1. Menu aktvitas PSB ( Pendaftaran Siswa Baru ) ini, melibatkan beberapa aktivtas di dalamnya seperti : Proses Penerimaan Siswa Baru, Pendataan Calon Siswa, Tahun Ajaran, Penempatan Siswa, dan Statistik Penerimaan Siswa Baru.

2. Menu Penilaian bagian akademik sekolah, melibatkan beberapa aktivitas proses penilaian diantaranya, Penilaian Pelajaran, Perhitungan Nilai Rapor, Nilai Rapor Siswa, Rata-rata RPP, Laporan Nilai Siswa dan Cetak Form Penilaian.

3. Menu Presensi akademik sekolah, dilakukan proses pendataan presensi harian dan presensi pelajaran. Presensi harian biasanya digunakan pada tingkat TK atau SD/MI, sedangkan presensi pelajaran biasanya digunakan pada tingkat SMP dan SMA/SMK.

4. Menu Pelajaran dilakukan untuk proses pendataan pelajaran - pelajaran yang diajarkan pada sekolah, penyusunan RPP, aturan perhitungan nilai rapor, dan penentuan jenis-jenis pengujian dari setiap pelajaran.

\section{b. Sistem Informasi Keuangan Sekolah}

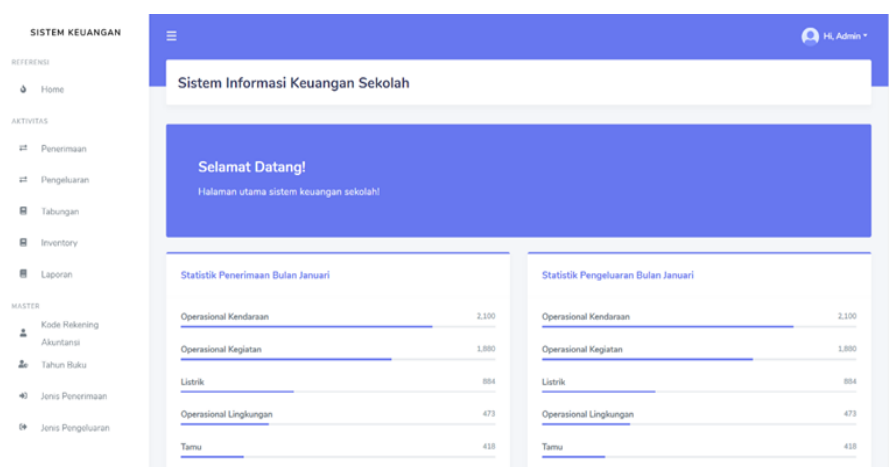

Gambar 7. Tampilan prototype sistem keuangan 
Pengembangan rancangan web service pada sistem informasi sekolah pada bagian keuangan sekolah terdapat beberapa aktivitas di dalamnya seperti Penerimaan, Pengeluaran, Tabungan, Inventory dan Laporan.

1. Menu Penerimaan bagian keuangan sekolah, melibatkan beberapa aktivitas yang menghandle proses penerimaan keuangan di antaranya, Proses Penerimaan Keuangan, Pendataan Transaksi Penerimaan Keuangan, penentuan tahun buku akuntansi dan laporan data transaksi penerimaan keuangan sekolah.

2. Menu Pengeluaran bagian keuangan sekolah, melibatkan beberapa aktivitas yang menghandle proses pengeluaran keuangan di antaranya, Proses Pengeluaran Keuangan, Pendataan Transaksi Pengeluaran Keuangan, juga berbagai laporan transaksi pengeluaran keuangan sekolah.

3. Menu Tabungan bagian keuangan sekolah, melibatkan beberapa aktivitas yang menghandle tabungan keuangan sekolah.

4. Menu Inventory bagian keuangan sekolah, melibatkan beberapa aktivitas yang menghandle proses pendataan barang - barang yang menjadi inventaris sekolah, dimana setiap barang akan dikelompokkan ke dalam beberapa grup barang.

5. Menu Pengeluaran bagian keuangan sekolah, melibatkan beberapa aktivitas yang menghandle proses pengeluaran keuangan di antaranya, Proses Pengeluaran Keuangan, Pendataan Transaksi Pengeluaran Keuangan, juga berbagai laporan transaksi pengeluaran keuangan sekolah.

6. Menu laporan keuangan sekolah, terdapat beberapa aktivitas keuangan pada periode tertentu yang direpresentasikan ke dalam bentuk laporan. Laporan keuangan terdiri dari laporan transaksi keuangan, laporan audit keuangan, laporan kas, laporan neraca, laporan transaksi keuangan, dan laporan buku besar.

\section{c. Sistem Informasi Perpustakaan Sekolah}

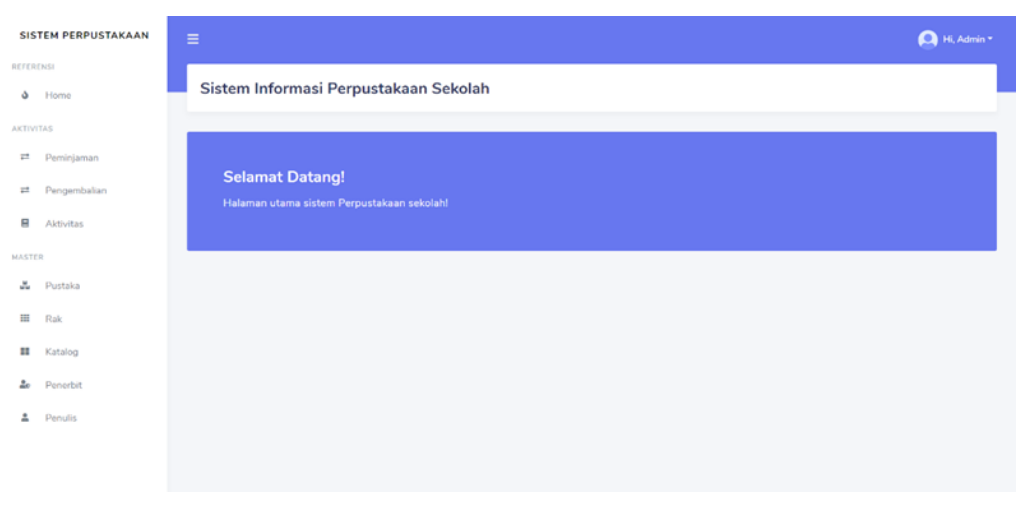

Gambar 8. Tampilan prototype sistem perpustakaan 
Pengembangan rancangan web service pada sistem informasi sekolah pada bagian perpustakaan terdapat beberapa aktivitas di dalamnya seperti peminjaman, pengembalian dan aktivitas.

1. Menu peminjaman ini, melibatkan beberapa aktivitas di dalamnya seperti proses peminjaman pustaka, pendataan peminjaman pustaka, riwayat peminjaman pustaka, dan berbagai laporan peminjaman pustaka.

2. Menu pengembalian ini, melibatkan beberapa aktivitas di dalamnya seperti proses pengembalian pustaka, pendataan pengembalian pustaka, riwayat pengembalian pustaka, dan berbagai laporan pengembalian pustaka.

3. Menu aktivitas, melibatkan beberapa aktivitas di dalamnya mengenai daftar aktivitas perpustakaan. Dari menu aktivitas perpustakaan dapat diperoleh informasi mengenai aktifitas dan kegiatan yang berlangsung di dalam perpustakaan.

\section{d. Sistem Informasi Kepegawaian Sekolah}

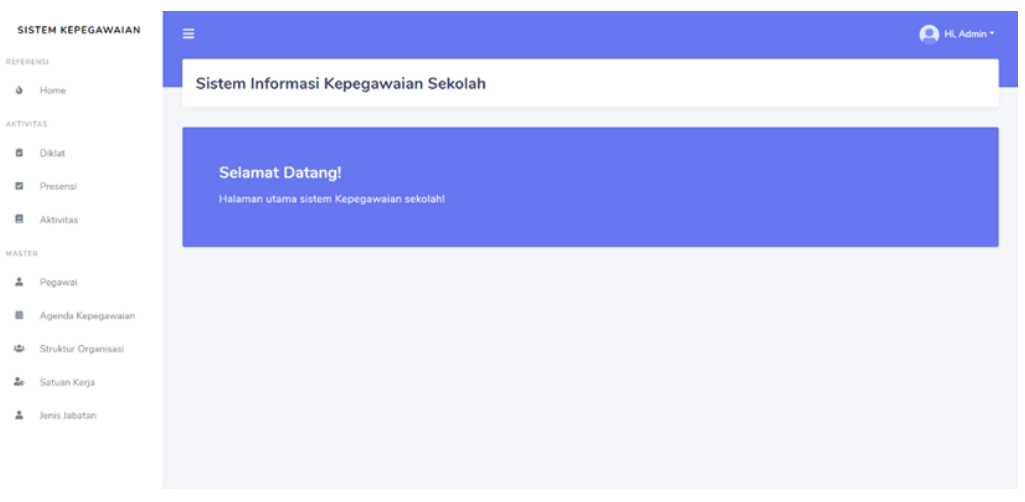

Gambar 9. Tampilan prototype sistem akademik

Pengembangan rancangan web service pada sistem informasi sekolah pada bagian kepegawaian terdapat beberapa aktivitas di dalamnya seperti diklat, presensi dan aktivitas.

1. Menu diklat, melibatkan beberapa aktivitas yang menghandle kegiatan pendidikan dan pelatihan untuk para pegawai, seperti diklat struktural dan diklat fungsional.

2. Menu presensi, melibatkan beberapa aktivitas yang menghandle presensi pada kepegawaian seperti, presensi harian, presensi jam mengajar, presensi lembur pegawai, dan rekapitulasi presensi pegawai.

3. Menu aktivitas, melibatkan beberapa aktivitas kepegawaian berupa daftar aktivitas kepegawaian. Dari menu aktivitas perpustakaan dapat diperoleh informasi mengenai aktifitas dan kegiatan yang berlangsung di dalam perpustakaan. 


\section{SIMPULAN}

Berdasarkan hasil pengujian dan analisa maka dapat diambil kesimpulan bahwa dengan adanya pengembangan rancangan web service pada sistem informasi sekolah, berbagai macam sistem yang terdapat pada sistem informasi sekolah dapat saling terintegrasi sehingga dapat mengurangi bahkan menghilangkan adanya duplikasi data, mengurangi resiko data hilang atau dicuri dan database menjadi lebih rapi. Selain itu, dengan implementasi web service, API dari sistem dapat terbuka untuk semua platform yang ingin mengakses atau menggunakan sistem tersebut.

Penulis menyadari bahwa penelitian yang dilakukan masih memiliki banyak kekurangan. Oleh karena itu, penulis mengajukan beberapa saran yang nantinya dapat membantu yaitu setiap sistem informasi pasti memiliki API nya tersendiri, untuk implementasi API menggunakan REST maka perlu dibuat detail endpoint untuk setiap modul yang terdapat di dalam setiap sistem informasinya.

\section{DAFTAR PUSTAKA}

[1] edhy, s. (2019). 14 Pengertian Sistem Informasi Menurut Para Ahli - DosenIT.com. Retrieved 8 September 2019, from https://dosenit.com/kuliah-it/sisteminformasi/pengertian-sistem-informasi-menurut-para- ahli

[2] W3C Working Group, 2004, Web Services Architecture, http://www.w3.org, 11 Februari, diakses tanggal 02 Desember 2019.

[3] M. Siregar dan J. Purba, "Membongkar Teknologi Pemrograman Web Service", Bandung: AplyIT, 2012.

[4] Y. Fauziah, "Aplikasi Iklan Baris Online menggunakan Arsitektur REST Web Service," TELEMATIKA, Vol. \%1 dari \%2Vol. 9, No. 2, p. 75 - 80, JANUARI 2013.

[5] Anonim. 2015. Introducing JSON. [Online]. Tersedia: http://json.org/. [Diakses 2 Desember 2019].

[6] Tansil Choiri, Nataniel Dengen, Islamiyah "Web Service Untuk Web Profil Smp Negeri 2 Rantepao Toraja Utara" Teknik Informatika, Fakultas Ilmu Komputer dan Teknologi Informasi, Universitas Mulawarman, Vol. 2, No. 1, Maret 2017

[7] Astika AyuningTyas, Ahmad Ashari, "Pemanfaatan Teknologi Web Service Untuk Integrasi Sistem Layanan Materi Pelayanan Terdistribusi", Jurnal Angkasa Jurusan Ilmu Komputer dan Elektronika, FMIPA UGM, Yogyakarta. VOLUME VIII, NOMOR 2, MEI 2016

[8] Raharjo, Budi, "Mudah Belajar PHP Teknik Penggunaan Fitur-Fitur Baru dalam PHP 5", Bandung:Informatika, 2015.

[9] Salim Akhbar, Rudy Firmansyah and Yulistia. "Sistem Informasi Pemesanan dan Penyewaan Mobil Berbasis Web Pada CV. Louhan Mobilindo". Jurusan Sistem Informasi, STMIK GI MD.

[10] Samiaji Sarosa, SE. and M.Info.Sys., Ph.D, "Metodologi Pengembangan Sistem Informasi", Jakarta Barat: Indeks Jakarta, 2017.

[11] BSNP, 2019, BSNP (Badan Standar Nasional Pendidikan), http://bsnpindonesia.org/, diakses tanggal 02 Desember 2019.

[12] Mochamed Fajar Ramadhani, "Pembangunan Aplikasi Informasi, Pengaduan, Kritik, Dan Saran Seputar Kota Cimahi Pada Platform Android”, Jurnal Ilmiah Komputer dan Informatika (KOMPUTA), Vol. 14, No. 01,2017 